\title{
THE EFFECT OF DRUGS ON IMPLANTATION IN RATS WITH AN INTRAUTERINE DEVICE IN ONE HORN OF THE UTERUS
}

\author{
M. ROY GHAUDHURY \\ Chulalongkorn Hospital Medical School, Bangkok, Thailand
}

(Received 15th Fuly 1974)

The mechanism of the antifertility effect of the IUD has not been clearly elucidated. Recent experimental results suggest that prostaglandins released by such a device could inhibit implantation (Chaudhuri, 1971; Saksena, Lau \& \& Castracane, 1974), either by expelling the blastocyst through uterine contractions or by exerting a luteolytic effect.

This hypothesis has been tested by administering acetyl salicylic acid and indomethacin, at dose levels known to prevent formation of prostaglandins, to rats with an IUD in one horn of the uterus. Similar experiments were carried out on rats treated with progesterone, $\mathrm{LH}$ or $\mathrm{LH}+$ prolactin which are known to counteract the luteolytic effect of prostaglandins (Fuchs \& Mok, 1973).

A silk thread suture was inserted into the lumen of one horn of the uterus as described by Tarak \& Chaudhury (1965) and the rats (150 to $200 \mathrm{~g}$ ) were allowed to mate 14 days after insertion of the suture. The day spermatozoa were detected in the early morning vaginal smear was termed Day 1 of pregnancy. A laparotomy was performed on Day 10 of pregnancy to determine the number of implantation sites in the control horn and in the horn with the suture.

The doses used, the route and time of administration of the drugs, and the number of implantation sites observed in the rats are shown in Table 1.

The results indicate that, in rats, the IUD does not appear to act by releasing prostaglandins from the endometrium of the uterus since there were no implantation sites in the horn with the IUD in animals in which indomethacin or acetyl salicylic acid would have prevented the synthesis of prostaglandins. These results confirm the findings of Chaudhuri (1973) with indomethacin.

It is interesting to note that $\mathrm{LH}$ at a dose level of $250 \mu \mathrm{g} / \mathrm{kg}$ twice a day inhibited implantation in the control horns of all seven rats. If this effect can be demonstrated in other species, including women, administration of LH or LH-RF might provide an additional method of contraception.

The author is grateful to Professor Charanpat Israngkun, Chairman of the Department of Obstetrics \& Gynaecology, Chulalongkorn Hospital Medical School, Bangkok, for providing facilities to carry out this work and to Professor Ranjit Roy Chaudhury for advice and suggestions for the work carried out. This study was supported by a grant from the Population Council, New York. 


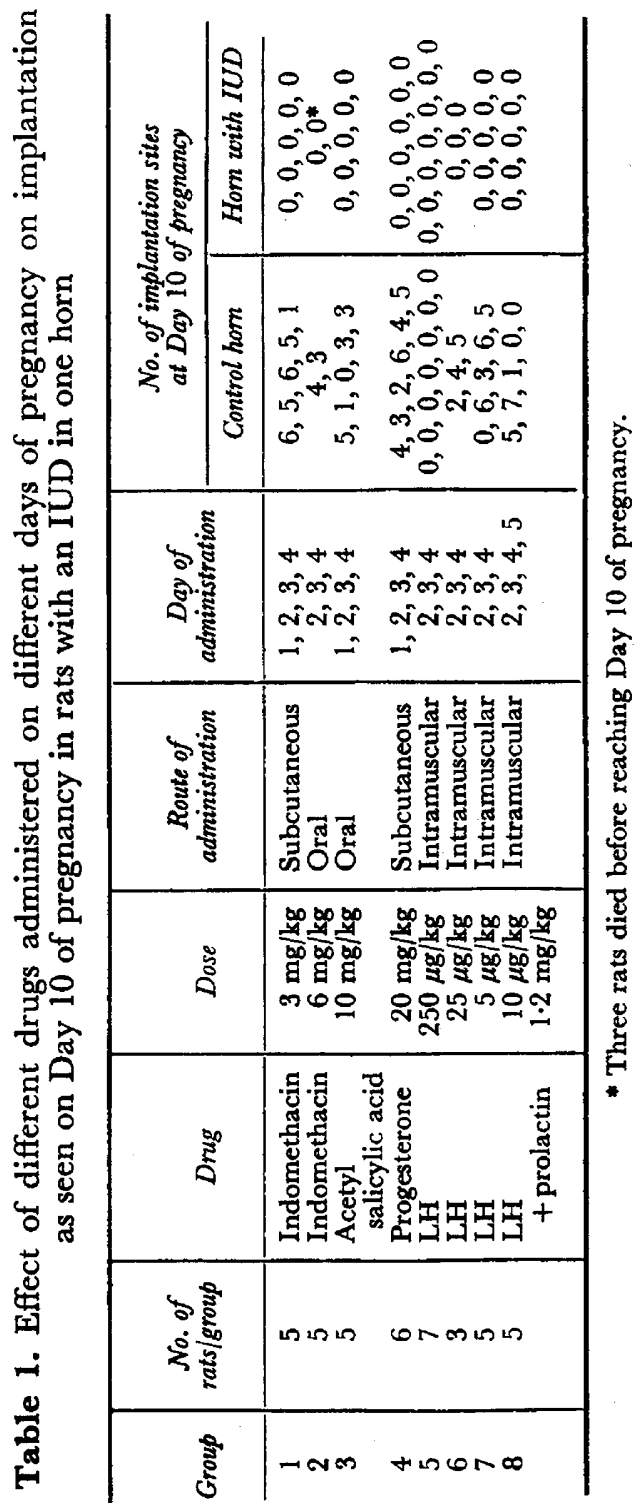




\section{REFERENCES}

Chaudhurr, G. (1971) Intrauterine device: possible role of prostaglandins. Lancet, i, 480.

Chaudhuri, G. (1973) Release of prostaglandins by the IUGD. Prostaglandins, 3, 773-784.

FucHs, A. R. \& MoK, E. (1973) Prostaglandin effects on rat pregnancy. II. Interruption of pregnancy. Fert. Steril. 24, 275-283.

Sarsena, S. K., Lau, I. F. \& Castragane, V. D. (1974) Prostaglandin mediated action of IUDs. Prostaglandins, 5, 97-106.

TARAk, T. K. \& Ghaudhury, R. R. (1965) Effect of an intrauterine silk thread suture on the fertility of female rats. Br. med. F. i, 31-32. 